Respiration 2015;90:263-264

DOI: $10.1159 / 000430826$

\section{Is There a Relationship between Apolipoprotein E Genetic Variants and Obstructive Sleep Apnea Syndrome? Consideration Needed from Evidence- Based Medicine}

\section{Jianrong Hu Chunlin Tu Ying Liu YuhuaFu}

Department of Respiratory Medicine, Jiading Central Hospital, Shanghai, China

Dear Editor,

We read the article by Uyrum et al. [1] with great interest. In this well-conducted study, Uyrum et al. elegantly detail how the specific apolipoprotein E (APOE) genotypes (i.e., APOE2 allele and APOE4 allele) are significantly associated with obstructive sleep apnea syndrome (OSAS). It is worth noting that in this study, the APOE2 allele had a 9.37-fold OSAS risk, and the APOE 4 allele had a 2.9-fold OSAS susceptibility.

First of all, we should congratulate Uyrum et al. on their splendid work focusing on APOE genotypes and OSAS susceptibility. However, some methodological approaches should be addressed.
First, the sample size of the study was relatively small (42 cases and 31 controls). We calculated the number of participants that would be required for $80 \%$ power to detect the ORs of the APOE2 and APOE4 alleles in a non-OSA population (alpha $=0.05)$ according to a recent meta-analysis [2]. When power was defaulted at $80 \%$ (type I error rate of 0.05), the percentages of APOE2 and 4 alleles in the control population were 13.2 and $29.1 \%$, respectively (observed from the studies). Studies with control/case ratios of 1, 2, 3, and 4 would need to include 149,349,112,179, 99,789, and 93,593 OSAS cases for APOE2, and 10,068, 7,534, 6,689, and 6,266 OSAS cases for APOE4 to detect an OR of 0.97 for APOE2 and an OR of 1.09 for APOE4, respectively. These estimates translated to total sample sizes of $298,698,336,537,399,156$, and 467,965 for APOE2, and 20,136, 22,602, 26,756, and 31,330 for APOE4. Second, the Hardy-Weinberg equilibrium of genotype distributions in control subjects was unexamined. In addition, we pooled all available data using Stata software (version 11.0; Stata Corp., College Station, Tex., USA). No association between APOE2/APOE4 and OSAS susceptibility was found $(\mathrm{OR}=1.00,95 \% \mathrm{CI}: 0.74,1.36$; $\mathrm{OR}=1.11$, 95\% CI: 0.88, 1.40 for APOE2 and APOE4, respectively; fig. 1, 2). Thus, the conclusion of this study should be reconsidered and might be more convincible if the authors added the aforementioned meta-analytic information. We believe that the added information will help clarify the actual relationship between APOE genotypes and OSAS risk.

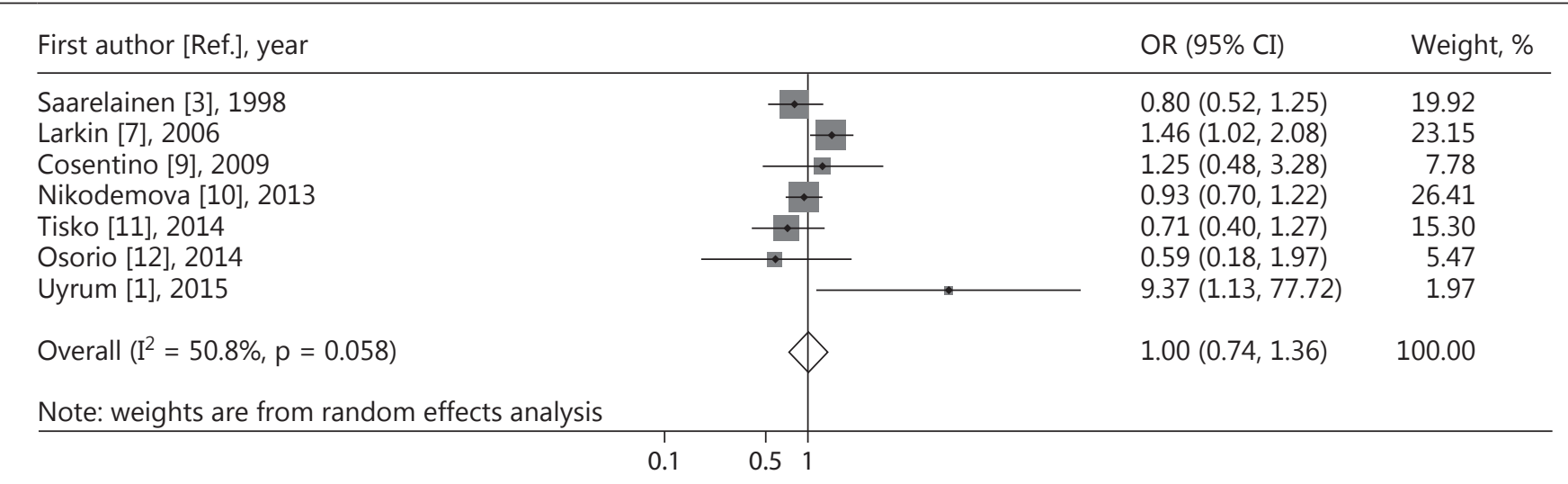

Fig. 1. Forest plot of the associations between the APOE2 allele and OSAS risk.

\section{KARGER 125}

2015 S. Karger AG, Base

0025-7931/15/0903-0263\$39.50/0

E-Mail karger@karger.com

www.karger.com/res
Jianrong $\mathrm{Hu}$

Department of Respiratory Medicine

Jiading Central Hospital

1 Chengbei Road, Shanghai 201800 (China)

E-Mail jianronghu@126.com 
First author [Ref.], year

OR $(95 \%$ CI)

Weight, \%

Saarelainen [3], 1998

Foley [4], 2001

Kadotani [5], 2001

Gottlieb [6], 2004

Larkin [7], 2006

Gozal [8], 2007

Cosentino [9], 2008

Nikodemova [10], 2013

Osorio [12], 2014

Uyrum [1], 2015

Overall $\left(I^{2}=67.9 \%, p=0.001\right)$

Note: weights are from random effects analysis

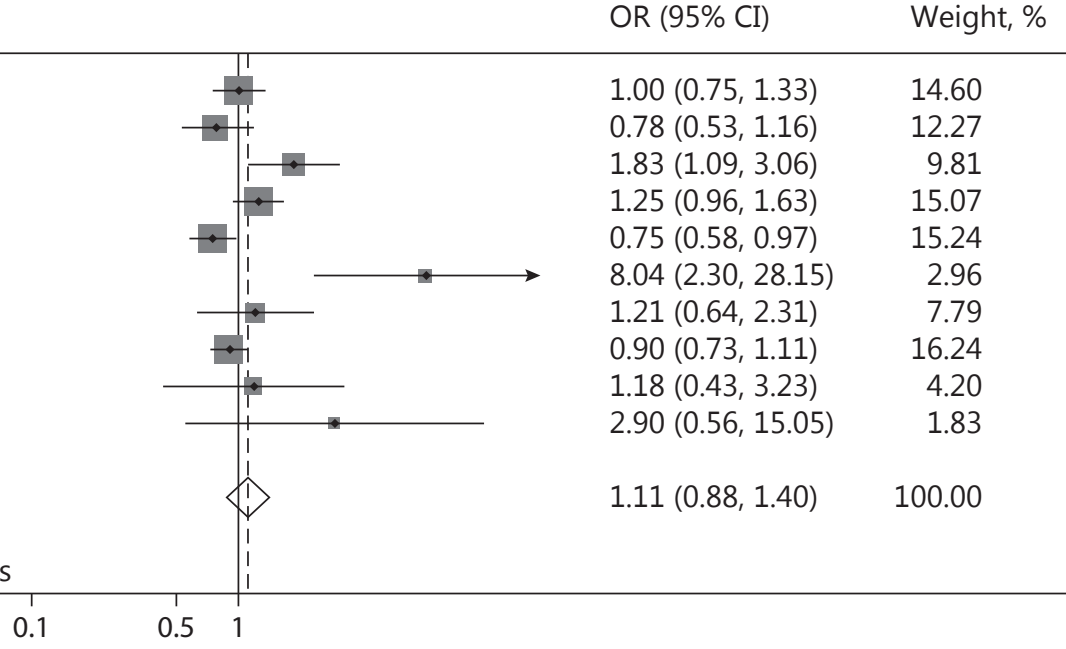

Fig. 2. Forest plot of the associations between the APOE4 allele and OSAS risk.

\section{References}

1 Uyrum E, Balbay O, Annakkaya AN, Gulec Balbay E, Silan F, Arbak P: The relationship between obstructive sleep apnea syndrome and apolipoprotein E genetic variants. Respiration 2015;89:195-200.

-2 Xu H, Qian Y, Guan J, Yi H, Yin S: No association between the ApoE ع2 and $\varepsilon 4$ alleles and the risk of obstructive sleep apnea: a systematic review and meta-analysis. Biomed Rep DOI: 10.3892/br.2015.425.

-3 Saarelainen S, Lehtimaki T, Kallonen E, Laasonen K, Poussa T, Nieminen MM: No relation between apolipoprotein $\mathrm{E}$ alleles and obstructive sleep apnea. Clin Genet 1998;53:147-148.

4 Foley DJ, Masaki K, White L, Redline S: Relationship between apolipoprotein E epsilon4 and sleep-disordered breathing at different ages. JAMA 2001;286:1447-1448.

5 Kadotani H, Kadotani T, Young T, Peppard PE, Finn L, Colrain IM, Murphy GM Jr, Mignot E: Association between apolipoprotein E epsilon4 and sleep-disordered breathing in adults. JAMA 2001;285:28882890.

-6 Gottlieb DJ, DeStefano AL, Foley DJ, Mignot E, Redline S, Givelber RJ, Young T: APOE epsilon4 is associated with obstructive sleep apnea/hypopnea: the Sleep Heart Health Study. Neurology 2004;63:664-668.

$\checkmark 7$ Larkin EK, Patel SR, Redline S, Mignot E, Elston RC, Hallmayer J: Apolipoprotein $\mathrm{E}$ and obstructive sleep apnea: evaluating whether a candidate gene explains a linkage peak. Genet Epidemiol 2006;30:101-110.
$>8$ Gozal D, Capdevila OS, Kheirandish-Gozal L, Crabtree VM: APOE epsilon 4 allele, cognitive dysfunction, and obstructive sleep apnea in children. Neurology 2007;69:243-249.

-9 Cosentino FI, Bosco P, Drago V, Prestianni G, Lanuzza B, Iero I, Tripodi M, Spada RS, Toscano G, Caraci F, Ferri R: The APOE epsilon4 allele increases the risk of impaired spatial working memory in obstructive sleep apnea. Sleep Med 2008;9:831-839.

10 Nikodemova M, Finn L, Mignot E, Salzieder N, Peppard PE: Association of sleep disordered breathing and cognitive deficit in APOE $\varepsilon 4$ carriers. Sleep 2013;36:873-880.

11 Tisko R, Sopkova Z, Habalova V, Dorkova Z, Slaba E, Javorsky M, Tkac I, Riha RL, Tkacova R: Effects of APOE genotype on serum lipids in obstructive sleep apnoea. Eur Respir J 2014;43:1097-1105.

12 Osorio RS, Ayappa I, Mantua J, Gumb T, Varga A, Mooney AM, Burschtin OE, Taxin Z, During E, Spector N, Biagioni M, Pirraglia E, Lau H, Zetterberg H, Blennow K, Lu SE, Mosconi L, Glodzik L, Rapoport DM: The interaction between sleep-disordered breathing and apolipoprotein E genotype on cerebrospinal fluid biomarkers for Alzheimer's disease in cognitively normal elderly individuals. Neurobiol Aging 2014;35:13181324. 